\title{
RESPONSES OF HUMAN PERIPHERAL LYMPHOCYTES TO SOLUBLE AND INSOLUBLE ANTIGENS OF CANDIDA ALBICANS
}

\author{
Seyedeh M. M. GetTNeR* AND D. W. R. Mackenzie \\ Mycological Reference Laboratory, London School of Hygiene and Tropical Medicine, \\ Gower Street, London WCIE 7 HT
}

Summary. Responses of peripheral lymphocytes from the blood of 20 healthy volunteers were determined in vitro by measurement of tritiated thymidine uptake in the presence of six different antigens prepared from Candida albicans. Crude antigens (disintegrated cells, culture filtrate) produced greater lymphoblast reactivity than purified preparations (cytoplasmic proteins, cell-wall mannan).

Reactions to soluble mannan were uncommon but the number of subjects who responded to them increased from one to 14 when the material was rendered particulate by adsorption on to latex particles. Lymphocyte responses were also elicited by intact, heat-killed yeast cells.

\section{INTRODUCTION}

Acquired immunological reactivity of man to Candida albicans is almost universal. With appropriate reagents and procedures, it can be demonstrated by the transformation of lymphocytes in vitro (Alford 1973; Foroozanfar, Yamamura and Hobbs 1974), and by the detection of antibodies reacting to candida antigens (Drake 1945). Serological tests are widely used in the recognition and monitoring of candida infections but these do not allow ready differentiation between tissue colonisation and invasion, and as yet there are no internationally accepted reference antigens.

Tests for cellular responsiveness to $C$. albicans are widely used in screening for individuals with impaired immunological reactivities. Shannon et al. (1966) reported that $94 \%$ of normal adults tested had cutaneous hypersensitivity after a candida skin test; Foroonzanfar et al. (1974) tested lymphoblast activity in vitro and found that lymphocytes from all the normal subjects tested underwent transformation in the presence of candida antigen.

It is not yet known which antigens are responsible for stimulation, although immune responses to different antigens are often dissimilar (Pepys et al. 1968; Longbottom et al. 1976). Studies with purified cytoplasmic proteins, from which all traces of mannan have been removed by the use of sepharose/con- 
canavalin-A columns (Lloyd, 1970) have suggested that this material sometimes poorly stimulates lymphocytes in vitro (Professor J. R. Hobbs, personal communication 1977). In preparing and supplying candida antigens for lymphocyte-transformation studies during the past decade, we have often been asked to avoid purification procedures because crude antigens have been found to be more effective than purified extracts. Crude antigens, however, are not amenable to precise chemical characterisation or standardisation. Use of an antigen that is simple rather than complex and which produces uniform rather than variable results when used to test for cell-mediated immunity in vitro, brings standardisation of test and reagent closer to reality.

The aims of this investigation were, therefore, to prepare different types of candida antigen, with particular emphasis on the reactivities of insoluble compared to soluble preparations, and to study their respective capacities to stimulate peripheral lymphocytes from healthy human subjects.

\section{MATERIALS AND METHODS}

Preparation of the antigens. Candida albicans strain NCPF3153 was used throughout and was maintained on slopes of glucose-peptone agar ( $2 \%$ glucose, $1 \%$ Bacto-peptone, $1.5 \%$ agar).

Whole-cell homogenate (CAD-6) was prepared from blastospores of C. albicans grown for 3 days in stirred glucose-peptone broth culture. After harvesting and washing, it was frozen at $-20^{\circ} \mathrm{C}$ for $24 \mathrm{~h}$, suspended in $0.4 \%$ ammonium hydrogen carbonate buffer at $p \mathrm{H} 7 \cdot 3$, and disrupted in a Dyno-mill Cell Disintegrator (Glen Creston, Carlisle Rd, London NW9 DHL). The crude suspension was centrifuged and the supernate concentrated by dialysis against $10 \%$ polyethylene glycol, centrifuged again and lyophilised.

Mannan (M) was prepared by the method of Peat, Whelan and Edwards (1961) and tested for antigenic activity by counterimmunoelectrophoresis against a rabbit antiserum with antibody to mannan. One or two distinct precipitin lines were obtained depending on the concentration of antigen used.

Latex particles were sensitised with mannan $(\mathrm{M}+\mathrm{L})$ as follows: a suspension of latex particles (Difco, $0.81 \mu \mathrm{m}$ ) was diluted 1 in 10 with glycine-saline buffer $p \mathrm{H} 8.2$; a solution of mannan, $20 \mathrm{mg} / \mathrm{ml}$ in glycine-saline buffer, was mixed with an equal volume of the latex suspension and left at $4^{\circ} \mathrm{C}$ for $24 \mathrm{~h}$. The sensitised latex particles were washed twice in glycine-saline buffer with centrifugation at $18000 \mathrm{~g}$ for $30 \mathrm{~min}$, then made up to the original volume with buffer and stored at $4{ }^{\circ} \mathrm{C}$. Approximately $25 \%$ of the mannan of the original suspension was bound to the latex particles, as determined by the method of Dubois et al. (1956). The sensitised latex was tested for antigenicity by agglutination (Mackenzie, Philpot and Proctor, 1980) with serum from a rabbit immunised with heat-killed cells of $C$. albicans and shown to contain antibody towards mannan.

Purified cytoplasmic protein (PP) from C. albicans strain NCPF3153 was obtained from the National Institute for Biological Standards and Control, Holly Hill, London NW3 6RB.

Antigen from culture filtrate (CF) was obtained from C. albicans grown in SML medium (Lee, Campbell and Buckley, 1975) for 7 days at $25^{\circ} \mathrm{C}$ in a rotary incubator. After centrifugation the supernate was concentrated against $30 \%$ polyethylene glycol at $4{ }^{\circ} \mathrm{C}$ overnight to $2 \%$ of its original volume. It was freeze dried and stored in vacuo. Its antigenic activity was tested by double-diffusion tests (Mackenzie et al., 1980) with rabbit and sheep antisera containing antibodies against $C$. albicans.

Whole-cell killed (WC) antigen was obtained from C. albicans grown on slants of $2 \%$ malt-extract agar incubated for $24 \mathrm{~h}$ at $28^{\circ} \mathrm{C}$. The growth was harvested and washed three times with sterile water; non-budding organisms of uniform size were collected by means of a sucrose density gradient. More than $95 \%$ of the harvested cells were non-budding when examined microscopically. They were adjusted to a concentration of $10^{6} / \mathrm{ml}$ with a haemocytometer and 
heat killed at $70^{\circ} \mathrm{C}$ for $1 \mathrm{~h}$. Non-viability was confirmed by the methylene-blue technique of Lehrer and Cline (1969) and by culture on glucose peptone agar.

Human subjects. Twenty healthy human volunteers were tested for their cellular responses to the six different preparations of $C$. albicans. The group consisted of eight females 25-65 years of age with an average age of 45 years and 12 males 20-55 years with an average age of 40 . They were bled by venepuncture from the antecubital vein in the forearm and their lymphocyte responses were determined by transformation studies in vitro. Prior exposure of all subjects to C. albicans was suggested by the presence of specific agglutinating antibodies in females (titres 16-64) and males (4-16).

Lymphocyte transformation. Venous blood $10-15 \mathrm{ml}$ was defibrinated in a sterile $20-\mathrm{ml}$ screw-capped tube (Sterilin) containing 10 glass beads. After centrifugation for 10 min at $200 \mathrm{~g}$ the plasma was transferred to a 5-ml screw-capped tube by a sterile pasteur pipette. The cells were resuspended in sterile Dulbecco phosphate-buffer saline $p \mathrm{H} 7.3$ and overlaid gently on 10 $\mathrm{ml}$ of Ficoll-Triosil (Nyegaard, Oslo, Norway) and centrifuged for $30 \mathrm{~min}$ at $400 \mathrm{~g}$. After centrifugation, erythrocytes and granulocytes were present in the sediment and lymphocytes at the interphase. The interphase was transferred by sterile pasteur pipette into a screw-capped tube, washed three times for $5 \mathrm{~min}$ each in phosphate-buffered saline and centrifuged at $200 \mathrm{~g}$. The cells were resuspended at the end of each wash in a Rotomixer (Fisons Ltd, Pharmaceutical Division, Loughborough) and finally resuspended in $5 \mathrm{ml}$ of RPMI 1640 culture medium (Difco) and counted in a haemocytometer. The cells were adjusted to $10^{6} / \mathrm{ml}$ with culture medium containing $10 \%$ homologous plasma.

Lymphocyte cell cultures were set up in duplicate for each of the test antigens in a sterile round-bottomed microtitre plate (Linbro, Flow Laboratories, Irvine, Strathclyde). The concentrations of antigens used for soluble antigens were 2000,200,20 and $2 \mu \mathrm{g} / \mathrm{ml}$. Particulate mannan was used in concentrations of $2500,250,25$ and $2.5 \mu \mathrm{g} / \mathrm{ml}$. The whole-cell killed antigen was used in concentrations of $10^{6}, 10^{5}, 10^{4}$ and $10^{3} / \mathrm{ml}$. Lymphocyte suspension $200 \mu \mathrm{l}$ and $10 \mu \mathrm{l}$ of each antigen concentration were added to each well except the control, which did not receive antigen. The plates were sealed with plate sealer (Flow Laboratories, Irvine, Strathclyde) and incubated at $37^{\circ} \mathrm{C}$ for 5 days.

Harvesting and counting was accomplished by adding $10 \mu \mathrm{l}$ of tritiated thymidine $(0 \cdot 2 / \mu \mathrm{Ci}$, Radiochemicals Centre, Amersham, Bucks) to each well with a Hamilton syringe for the last $24 \mathrm{~h}$ of culture. The plate was resealed and the cells were resuspended then collected with a cell harvester (as designed and used at the Department of Immunology, Institute of Child Health, Great Ormond Street, London) on to Whatman $\mathrm{CF} / \mathrm{C}$ filters $2.5 \mathrm{~cm}$. The filters were placed in plastic scintillation vials (Packard, Caversham, Reading, Berks) and left at room temperature to dry. Scintillation fluid, $6 \mathrm{ml}$, was added to each vial which was then capped. Each vial was counted for 4 min in a beta counter (1210 ultrobeta, LKB Instruments Ltd, Addington Rd, South Croydon). A background count and a hexadecane standard (Radiochemicals Centre, Amersham, Bucks) was added to each run and results expressed as disintegrations per minute (dpm) corrected for the efficiency of the counter and the background.

For each antigen-cell system, the ratio dpm with antigen: dpm without antigen was designated the stimulation index. An index of more than 2 was considered to be significant.

\section{RESULTS}

The DPM counts of the tritiated-thymidine labelled cells responding to each antigen were recorded only when they were significantly higher than that of the control, not exposed to antigen, in the same series. The lymphocytes of the volunteers were tested with all six antigens, and those from 19 of the 20 subjects tested responded to the antigens of $C$. albicans (tables I and II):

Comparison of the six antigenic preparations showed that culture filtrate, the whole-cell homogenate and particulate mannan were superior to purified protein and soluble mannan. The order of stimulation capacity was in the 


\section{TABLE I}

Responses of lymphocytes from human subjects to six different antigens of C. albicans

\begin{tabular}{l|cc}
\hline & \multicolumn{2}{|c}{ Number of subjects } \\
\cline { 2 - 3 } Antigen & tested & $\begin{array}{c}\text { responding } \\
\text { (and percentage) }\end{array}$ \\
\hline CAD-6 & 20 & $18(90 \cdot 0)$ \\
M & 19 & $1(5 \cdot 3)$ \\
M+L & 17 & $14(82 \cdot 4)$ \\
PP & 12 & $3(25 \cdot 0)$ \\
CF & 19 & $18(94 \cdot 7)$ \\
WC & 15 & $13(86 \cdot 7)$ \\
\hline
\end{tabular}

CAD-6 $=$ whole-cell homogenate; $\mathrm{M}=$ mannan; $\mathrm{M}+\mathrm{L}=$ mannan +latex particles; $\mathrm{PP}=$ purified cytoplasmic protein; $\mathrm{CF}=$ culture filtrate; $\mathrm{WC}=$ whole cell.

TABLE II

Stimulation indices of six antigens of candida on peripheral lymphocytes from 20 human subjects

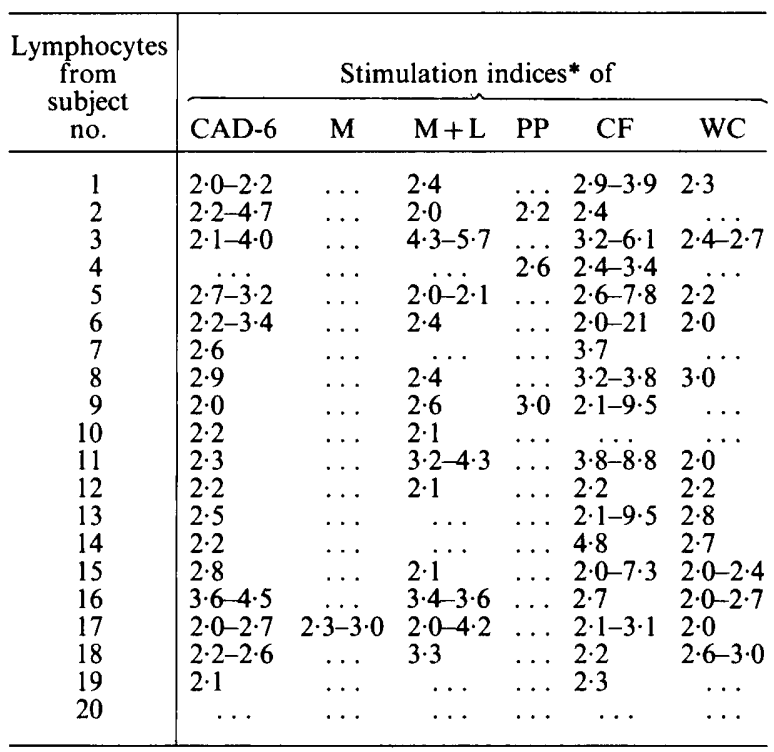

For explanation of abbreviations see footnote to table I.

$\ldots=<2 \cdot 0$.

* For calculation see Methods.

sequence: $\mathrm{CF}>\mathrm{CAD}-6>\mathrm{WC}>\mathrm{M}+\mathrm{L}>\mathrm{PP}>\mathrm{M}$, provoking responses in $94.7 \%, 90.0 \%, 86 \cdot 6 \%, 82.4 \%, 25 \cdot 0 \%$ and $5.2 \%$ of subjects respectively (table I). Thus, particulate and crude antigens were found to be superior to purified and soluble preparations in promoting lymphocyte transformations.

The most potent antigens, CF, CAD -6 and $M+L$, stimulated the lymphocytes of some subjects even when used at a concentration of $0 \cdot 1 \mu \mathrm{g} / \mathrm{ml}$. $\mathrm{PP}, \mathrm{M}$ and WC failed to stimulate at concentrations of less than $10 \mu \mathrm{g} / \mathrm{ml}$ or $10^{3}$ cells/ml (table III). 
TABLE III

Responses of lymphocytes from 19 subjects to candida antigens at different dilutions

\begin{tabular}{|c|c|c|c|c|}
\hline \multirow[t]{2}{*}{ Antigen } & \multicolumn{4}{|c|}{$\begin{array}{c}\text { Number of subjects res- } \\
\text { ponding at } \\
\text { indicated final } \\
\text { concentration }\end{array}$} \\
\hline & \multicolumn{4}{|c|}{$\mu \mathrm{g} / \mathrm{ml}$} \\
\hline $\begin{array}{c}\text { Soluble } \\
\text { CAD-6 } \\
\text { M } \\
\text { PP } \\
\text { CF } \\
\end{array}$ & $\begin{array}{r}100 \\
16 \\
1 \\
3 \\
17\end{array}$ & $\begin{array}{r}10 \\
9 \\
1 \\
0 \\
12\end{array}$ & $\begin{array}{l}1 \\
4 \\
0 \\
0 \\
8\end{array}$ & $\begin{array}{c}\mathbf{0 . 1} \\
1 \\
0 \\
0 \\
6\end{array}$ \\
\hline \multirow{3}{*}{$\begin{array}{r}\text { Particulate } \\
\mathrm{M}+\mathrm{L} \\
\end{array}$} & \multicolumn{4}{|c|}{$\mu \mathrm{g} / \mathrm{ml}$} \\
\hline & $\begin{array}{l}125 \\
12\end{array}$ & $\begin{array}{r}12 \cdot 5 \\
5\end{array}$ & $\begin{array}{c}1 \cdot 25 \\
3\end{array}$ & $\begin{array}{c}0 \cdot 125 \\
2\end{array}$ \\
\hline & \multicolumn{4}{|c|}{ cells/ml } \\
\hline $\begin{array}{c}\text { Intact cells } \\
\text { WC }\end{array}$ & & $\begin{array}{r}10^{3} \\
4\end{array}$ & $\begin{array}{c}10^{2} \\
0\end{array}$ & $\begin{array}{c}10 \\
0\end{array}$ \\
\hline
\end{tabular}

For explanation of abbreviations see footnote to table I.

Latex particles proved suitable for rendering mannan particulate and, in contrast to soluble mannan, stimulated the lymphocytes of most of the subjects tested. The percentage of reactors to soluble mannan and to mannan adsorbed on latex was $5 \cdot 2 \%$ and $82.4 \%$ respectively. To eliminate the possibility of non-specific stimulation produced by latex alone, lymphocyte cultures were exposed repeatedly to untreated latex particles, which never caused stimulation.

\section{Discussion}

In this study, the lymphocytes of most human subjects were found to respond to the crude, particulate or culture filtrate antigens of $C$. albicans. Other investigators have already shown that lymphocytes from a high percentage of the normal population are stimulated by candida antigens (Alford, 1973; Foroozanfar et al., 1974; Frisk, von Stedingk and Wasserman, 1974).

We found that the culture filtrate, crude antigen and latex-absorbed mannan were superior to purified protein, soluble mannan and whole cells in potency and in magnitude of response, in stimulating lymphocytes from healthy subjects. Intact, heat-killed cells of $C$. albicans also caused some stimulation but to a lesser degree. The least potent antigens in the system studied were cytoplasmic proteins and soluble mannan with which the lymphocyte-stimulation index never exceeded the arbitrary level of significance, i.e., twice the control level. The fact that mannan rendered particulate by adsorption on to latex was stimulatory is compatible with the suggestion 
that the physical configuration of a stimulating antigen is important in inducing lymphocyte transformation in sensitised cells. Our findings suggest that structural changes in an antigen or its mode of presentation to lymphocytes influences its stimulatory effect.

Mannan, the predominant cell-wall polysaccharide antigen of C. albicans is a highly branched polymer of mannose consisting of an $\alpha 1 \rightarrow 6$ linked backbone with many side chains consisting of $\alpha 1 \rightarrow 2$ and $\alpha 1 \rightarrow 3$ linked oligosaccharides (Yu et al., 1967; Gorin and Spencer, 1968). Soluble mannan by itself may not be processed by macrophages and this may explain the failure of lymphocytes to transform. However, mannan adsorbed on latex particles becomes functionally particulate and its antigenic determinants appear to become more readily available and recognised. A particulate antigen is likely to be more effective in establishing multiple bonding between antigenic determinants and lymphocyte receptors. In addition, particulate bound antigens may not dissociate as rapidly as soluble antigens.

Soluble antigens are usually poor evokers of T-cell response and, according to Sultzer and Nilsson (1972) and Cohen et al. (1975), tend to induce mitogenesis of B cells. The fact that aggregated materials are better recognised by $T$ cells was demonstrated by Möller (1969). He found that soluble antigen such as human serum albumin and mouse gamma globulin, when aggregated with their corresponding antibody, stimulated DNA synthesis in the normal human lymphocyte cultivated in vitro, whereas antibody alone or antigen alone had no effect, or a negligible effect. Zabriskie and Falk (1970) exposed tuberculin-sensitised human and rat lymphocytes to various products of tubercle bacilli and observed a significant response of sensitised lymphocytes to intact tubercle bacilli and negligible inhibition of migration when purified protein derivative (PPD) was used. Nilsson and Möller (1972) showed that PPD-tuberculin adsorbed to bentonite always stimulated stronger lymphocyte responses than soluble PPD.

The same could be true for purified proteins of $C$. albicans which, if linked on to latex or other inert particles, might become better stimulants for sensitised lymphocytes. One problem, which may be troublesome in practice, is the polyvalent nature of the cytoplasmic proteins of $C$. albicans. With so many different proteins present in such extracts there could be differences in their degree of attachment to the inert carrier and their retention of mitogenic reactivity when adsorbed on to latex particles. Because it is still not known which, if any, of the antigens detectable in cytoplasmic extract by orthodox serological tests are of diagnostic significance, it would be a major and perhaps impracticable undertaking to determine the adsorbtion and stimulatory qualities of each of the many protein or glycoprotein antigens in a cytoplasmic extract.

The superiority of a crude and complex antigen over a pure and simple one was shown in this study. The observation that the crude antigen CAD-6 proved a good stimulant of lymphocytes was probably due to the physical as well as to the chemical complexity of its antigenic components. It can be assumed that it contains numerous antigenic determinants which are easily 
recognised by lymphocytes and capable of inducing multiple bonding with cell receptors. It is also likely that crude antigen contains lipids which may act as adjuvants in the aquisition of stimulation.

Frisk et al. (1974), using different antigenic preparations of C. albicans, found that glucomannan protein of the cell wall was more potent in stimulating DNA synthesis of sensitised lymphocytes than the cytoplasmic antigen. Zawisza-Zenkteler and Zamiechowska-Miazga (1974) studied the effects of three different antigens of $C$. albicans on blast formation of rabbit lymphocytes and found a relationship between the chemical composition of different fractions and their stimulatory activity. Thus the glycoprotein fraction induced transformation similar to that associated with whole cells of $C$. albicans while glucomannan was inactive.

The stimulatory effect of culture filtrate is considered to be due to the presence of one or more antigens that are potent elicitors of lymphocyte stimulation. Although particles such as ribosomes and membrane fragments may be present in the culture filtrate, it is nevertheless likely that the critical quality is chemical rather than physical. The fact that culture filtrate is a product of secretion and excretion of living organisms makes it a more suitable lymphocyte stimulant. This metabolic product may be similar to the one produced in vivo as the growing organism encounters the host tissue.

The comparative inferiority of the non-viable heat-killed organism to stimulate in high dilution is presumed to be due to the large size of the particle, which would make presentation of antigen difficult. However, the intact whole cell may lack molecular complexity and may not have enough antigenic determinants exposed on its surface or perhaps the stimulating property has been modified by heat.

By reducing the number of the blastogenic antigens present in a whole-cell extract of C. albicans to one principal component (mannan), and by the use of a carrier particle of uniform, nature and size, a step has been taken towards the development of a lymphoblast reagent standardised in terms of physical and chemical nature on the one hand, and reactivity on the other. The method for conversion from soluble to insoluble forms of a single immunogen may have wider application in the study of lymphocyte reactivity to antigens derived from microbial and other sources.

Acknowledgements are made of the assistance received during this study from $\mathrm{Mr}$ A. G. J. Proctor of the Mycological Reference Laboratory, the staff of the Department of Immunology at the Institute of Child Health (notably Professor J. Soothill and Miss Lorna Layward), Dr W. Brighton of the National Institute for Biological Standards and Control, and Professor J. Hobbs of the Westminster Hospital. This work was supported by the Medical Research Council and formed part of a Ph.D thesis submitted to the University of London by S.M.M.G.

\section{REFERENCES}

ALFORD, R. H. 1973. Transformation of lymphocytes of normal and hospitalized adults by Candida albicans extract. Proc. Soc. exp. Biol. Med., 144, 826.

Cohen, J. J., Rodriguez, G. E., Kind, P. D. And Campbell, P. A. 1975. Listeria cell wall fraction: a B cell mitogen. J. Immun., 114, 1132. 
Drake, C. H. 1945. Natural antibodies against yeast-like fungi as measured by slide agglutination. J. Immunol., 50, 185.

Dubois, M., Gilles, K. A., Hamilton, J. K., Rebers, P. A. and Smith, F. 1956. Colorimetric method for determination of sugars and related substances. Analyt. Chem., 28, 350.

ForoOnZanfar, N., Yamamura, M. AND HobBS, J. R. 1974. Standardization of lymphocyte transformation to Candida immunogen. Clin. exp. Immun., 16, 301.

Frisk, A., vON STEDINGK, L.-V. AND WASSERMAN, J. 1974. Lymphocyte stimulation in Candida albicans infections. Sabouraudia, 12, 87.

GORIN, P. A. J. AND SPENCER, J. F. T. 1968. Structural chemistry of fungal polysaccharides. Adv. carbohyd. Chem., 23, 367.

LeE, K. L., CAMPBell, C. C. AND BUCKLEY, H. R. 1975. An amino acid liquid synthetic medium for the development of mycelial and yeast forms of Candida albicans. Sabouraudia, 13, 148.

LeHRER, R. I. AND Cline, M. J. 1969. Interaction of Candida albicans with human leukocytes and serum. J. Bact., 98, 996.

LLOYD, K. O. 1970. The preparation of two insoluble forms of the phytohemagglutinin concanavalin A, and their interactions with polysaccharides and glycoproteins. Archs. Biochem. Biophys., 137, 460.

Longbottom, J. L., Brighton, W. D., Edge, G. And Pepys, J. 1976. Antibodies mediating type I skin test reactions to polysaccharide and protein antigens of Candida albicans. Clin. Allerg., 6, 41.

Mackenzie, D. W. R., Philpot, C. M. and Proctor, A. G. J. 1980 . Basic serodiagnostic methods for diseases caused by fungi and actinomycetes. PHLS monograph series no. 12 H.M.S.O., London.

MöLLER, G. 1969. Induction of DNA synthesis in normal human lymphocyte cultures by antigen-antibody complexes. Clin. exp. Immun., 4, 65 .

NilsSON, B. S. AND MölLeR, G. 1972. Reactivity of human lymphocytes to aggregated and non-aggregated PPD-tuberculin. Cell. Immun., 5, 555.

Peat, S., Whelan, W. J. and EdWards, T. E. 1961. Polysaccharides of baker's yeast. Part IV. Mannan. J. chem. Soc., 1, 29.

Pepys, J., Faux, J. A., Longbottom, J. L., McCarthy, D. S. and Hargreave, F. E. 1968. Candida albicans precipitins in respiratory disease in man. J. Allerg., 41, 305.

Shannon, D. C., Johnson, G., Rosen, F. S. And Austen, K. F. 1966. Cellular reactivity to Candida albicans antigen. New Engl. J. Med., 275, 690.

SultZer, B. M. AND NilsSON, B. S. 1972. PPD tuberculin-a B-cell mitogen. Nature new Biol., 240, 198.

Yu, R. J., Bishop, C. T., CoOper, F. P., Hasenclever, H. F. ANd Blank, F. 1967. Structural studies of mannans from Candida albicans (serotypes A and B), Candida parapsilosis, Candida stellatoidea and Candida tropicalis. Can. J. Chem., 45, 2205.

ZABRISKIE, J. B. AND FALK, R. E. 1970. In vitro reactivity of lymphocytes to particulate and soluble antigens. Nature, Lond., 226, 943.

ZAWISZA-ZeNKTELER, W. AND ZAMIECHOWSKA-MiaZGA, J. 1974. Response of peripheral blood lymphocytes from rabbits to Candida albicans antigens. Bull. Acad. polon. Sci., 22, 293. 